\title{
THE HEMOGLOBIN LEVEL AS A PROGNOSTIC FACTOR IN PATIENTS WITH NON- SMALL CELL LUNG CANCER TREATED WITH GEMCITABINE AND CIS- PLATINUM
}

\author{
Deyan Nikolov Davidov, \\ Department of Chemotherapy, UMHAT- Dr. G. Stranski, \\ Medical University, Pleven, Bulgaria
}

\section{SUMMARY}

Objective: Anemia is observed in various malignancies including non- small cell lung cancer /NSCLC/ and is considered to be a poor prognostic factor. The aim of this study is to investigate whether there is a correlation between anemia, other clinic- pathological factors and survival in patients with advanced NSCLC treated with Gemcitabine / cisPlatinum- containing chemotherapy.

Methods: Seventy eight consecutive patients with advanced NSCLC treated in Department of Chemotherapy, UMHAT- Dr. G. Stranski, Medical University- Pleven between 2006- 2008 were retrospectively analyzed. Of those, 27 patients $134,6 \% /$ had low hemoglobin $/ \mathrm{HB} /$ level $(<120 \mathrm{~g} / \mathrm{L}$ for men and $<110 \mathrm{~g} / \mathrm{L}$ for women) prior to start chemotherapy. The HB levels were obtained at the time of their first visit to the hospital. All patients received chemotherapy regimen consists of intravenous administration of Gemcitabine $1250 \mathrm{mg} / \mathrm{m} 2$ day 1 and 8 and cis- Platinum $80 \mathrm{mg} / \mathrm{m} 2$ day 1 with repetition over 21 days. Survival analysis was evaluated by Kaplan- Meier test.

Results: The median survival time for all patients was 9,5 months. The median survival time for patients with low HB levels was 7,6 months versus 11,3 months in patients without anemia $/ \mathrm{p}<0.05 /$. There was a significant correlation between anemia and clinical stage or performance status / $\mathrm{p}<0.05 /$.

Conclusions: These results indicate that patients without anemia have significantly higher survival rate. Pretreatment HB level appears to be a useful prognostic indicator for survival in patients with inoperable NSCLC treated with chemotherapy.

Key words: Hemoglobin, Prognostic factors, Non small cell lung cancer, Chemotherapy, Survival.

\section{INTRODUCTION}

Lung cancer is the leading cause of cancer deaths among both men and women in the world. Non small cell lung cancer (NSCLC) represents approximately $75-85 \%$ of all lung cancer cases. Approximately, two- thirds of lung cancer patients have advanced or metastatic stage at diagnosis (1). Patients with stage III- IV NSCLC have a median survival time of 4- 5 months without treatment, and 1- year survival rate is only $10 \%$ to $20 \%$ (2). The treatment options for these patients are limited although platinum- based chemotherapy has been shown to provide survival and quality of life benefits. Overall 2 - year survival rates for this group remain $<15 \%$ (3). Newer chemotherapy combinations like Gemcitabine- Cisplatincontaining regimens showed a response rate of $19-32 \%$ and a median survival time of 7,9 to 11,3 months (4). The difference in outcome among patients with the same clinical stage of the disease suggests that advanced NSCLC is a heterogeneous disease and the survival depend of some patients characteristics as anemia, platelet counts, weight loss, concomitant diseases etc. (5).

Anemia is a common finding in cancer patients. Up to $30 \%$ of patients with different types of tumors have been reported to suffer from anemia (6). This can be related to the disease process itself or to its treatment, whether it is chemotherapy or radiotherapy. The factors associated with anemia itself encompass disorders of iron metabolism (7), reduced numbers of erythroid progenitor cells in the bone marrow, increased levels of inflammatory cytokines (8), extracorpuscular hemolysis, catabolism of patients with tumor burden, and relative deficiency of erythropoietin (6). Generally, the anemia is considered within the category of anemia of chronic diseases as normocytic and normochromic (7). The association of decreased hemoglobin levels with decreased survival has been demonstrated by randomized, controlled trials and large, community- based studies (9).

The aim of this study was to investigate the value of pre-treatment hemoglobin (HB) level as prognostic factor for survival in patients with advanced NSCLC treated with Gemcitabine and cis- Platinum containing chemotherapy regimen.

\section{PATIENTS AND METHODS}

Seventy- eight consecutive patients with advanced or metastatic NSCLC, treated in the period 2006- 2008 in Department of Chemotherapy, UMHAT- Dr. G. Stranski, 
Medical University- Pleven, were retrospectively analyzed. All patients were between 18 and 75 years of age; with morphologically documented NSCLC; advanced or metastatic disease; life expectancy of minimum three months; World Health Organisation (WHO) performance status 0 to 2; no prior chemotherapy or radiotherapy; adequate bone marrow function (absolute granulocyte count $>1,5 \times 10^{9} / \mathrm{L}$, platelet count $>140 \times 10^{9} / \mathrm{L} /$ as well as normal renal (serum creatinine level $<1,5 \mathrm{Mmol} / \mathrm{L}$ ) and hepatic function (serum bilirubin level $<21 \mathrm{Mmol} / \mathrm{L}$ ); absence of active infections; no overt cardiac disease. All patients were staged by computed tomography scan and radiography of the chest.

The anemia was defined as a HB level $<120 \mathrm{~g} / \mathrm{L}$ in men and $<110 \mathrm{~g} / \mathrm{L}$ in women. The pretreatment HB levels were obtained at the first visit to hospital prior to start chemotherapy. HB levels were analyzed by automated complete blood cell counting devices on ethylenediamine tetra- acetic acid (EDTA) - anti- coagulated blood. In our laboratory, the $95 \%$ confidence limit (normal range) of serum hemoglobin level is defined as $120-160 \mathrm{~g} / \mathrm{l}$ for men and 110 $150 \mathrm{~g} / 1$ for women.

Chemotherapy regimen consists of Gemcitabine of 1250 $\mathrm{mg} / \mathrm{m} 2$ by intravenous infusion day 1 and 8 and cis- Platinum $80 \mathrm{mg} / \mathrm{m} 2$ with hyperhydratation on day 1 . Treatments were repeated every 3 weeks up to six cycles and were stopped in the event of disease progression, serious adverse events or request by the patient. All patients received pre- medication with antiemetic drugs (5- HT antagonists) before administration of chemotherapy.

Patients were evaluated for tumor response before treatment and after every two courses of chemotherapy. Tumor response was evaluated according to WHO response criteria (10). Response was defined as complete response (CR), partial response (PR), no change (NC), or progressive disease (PD). Objective tumour response included both confirmed CR and PR. Safety was assessed using the WHO toxicity criteria (11). The duration of response was calculated from the day of the start of treatment to disease progression; overall survival was measured from study entry to death. The time to disease progression was calculated from study entry until the day of the first evidence of disease progression.

The chi- square test was used to analyze the correlations between anemia and other clinic- pathological factors. The actuarial survival was estimated by the method of Kaplan and Meier (12). Prognostic factors were analyzed using the Cox proportional hazard model. A $\mathrm{P}$ value $<0,05$ was considered to indicate statistical significance.

\section{RESULTS}

A total of 78 patients were recruited in the study over a 24- month's period. All patients regardless of their length of treatment were included in analysis. Tumor response was evaluated for all patients who received at least one course of chemotherapy. Baseline demographic and disease characteristics are summarized in Table 1 . The median age of patients was 56,8 years (range $41-76$ years) and $42 \%$ of patients were $>65$ years. The male/ female ratio was $84,3 \%$ to $15,7 \%$. Median WHO- performance status score was 1 (range 0-2). Median duration of treatment was 7,5 months. The follow- up period was 12 months.

The resulting antitumor effects are presented in Table 2. The overall survival was 9,5 months with overall response rate (ORR) of $32,1 \%$ ( 25 of 78 patients), including four complete and twenty one partial remissions. The median duration of response was 5,1 months. Median time to disease progression was 6,2 months.

Among all patients $27(34,6 \%)$ were with low HB level (24 men and three women) prior start of chemotherapy. Survival was significantly shorter in patients with anemia (median survival time 7,6 months) compared with those without this finding (median survival time 11,3 months) ( $p<$ $0,05)$,. Furthermore, the severity of anemia significantly correlates survival (table 3). Multivariate analysis of prognostic factors using the Cox proportional hazard model revealed that anemia $(\mathrm{p}=0,0002)$, WHO performance status $(p=0,001)$, and clinical stage $(p=0,0002)$ appeared to have independent prognostic significance. Age and sex appeared to have no significant effect on survival (table 4).

The relation between HB level and other clinicpathologic factors is shown in table 5. There was a significant correlation between anemia and clinical stage of disease $(p<$ $0,05)$ and anemia and WHO- performance status $(\mathrm{p}<0,05)$. Low HB levels did not correlate significant with gender, age or histological type of the tumor.

\section{DISCUSSION}

In the current study we evaluated efficacy and safety of the combination of Gemcitabine cis- Platinum as first- line chemotherapy for patients with NSCLC. Response rate- 34,2\% is promising. These results are comparable with previously published data. In these studies response rate were 40- 56\% with time to progression of 6- 8 months. Tumour control / $\mathrm{CR}+\mathrm{PR}+\mathrm{SD} /$ was achieved in $75,6 \%$ of patients $(\mathrm{N}=59)$ with survival duration- 10,4 months and is similar to other reports $(13,14)$

The prevalence of anemia in patients with various type of cancer was reported to be $26-86 \%$ at the time of diagnosis (15), which was comparable with the results obtained in this study. Our results also suggest that anemia is more common in patients with advanced clinical stage and with poor WHO performance status.

In addition, we demonstrated that the presence of anemia prior to start chemotherapy is an independent prognostic factor in patients with NSCLC using the Cox proportional hazard model. It has been already reported that low HB level is associated with shorter survival in patients with several types of cancer (16).

The reason for the poor prognosis in NSCLC patients 
with anemia have not been clarified yet. Tumour cells are known to secrete soluble molecules such as interferon gamma, interleukin-1 and tumour necrosis factor, which may develop anemia in cancer patients by haemolysis, suppression of erythropoesis and impairment of erythropoietin response on erythroid progenitor cells. Accordingly, anemia may be regarded as a paraneoplastic phenomenon. Thus patients with anaemia might have biologically more aggressive tumour cell clones compared to patients without anemia.

In conclusion, we demonstrated that anemia was frequently observed in patients with advanced NSCLC at the first visit in the hospital and survival was significantly shorter in patients with anemia compared with patients without it. Furthermore, we showed that survival of advanced NSCLC patients was independently influenced by pre-treatment serum HB levels using multivariate analysis. These results suggest that anemia determined at the time of first presentation is a useful indicator of the prognosis in patients with advanced NSCLC treated with chemotherapy.

Table 1. Patient characteristics

\begin{tabular}{|l|c|}
\hline Patient characteristics & Number of patients- 78 \\
\hline Age (years) & $41-76$ \\
\hline Sex & $66(84,6 \%)$ \\
Males & $12(15,4 \%)$ \\
Females & \\
\hline Dominant site of metastasis & $36(46,1 \%)$ \\
Pleura & $44(56,4 \%)$ \\
LiverLung & $23(29,5 \%)$ \\
Bone & $19(24,4 \%)$ \\
Soft tissue & $5(6,4 \%)$ \\
Other & $4(5,1 \%)$ \\
\hline Lost weight & $38(48,7 \%)$ \\
$<5 \%$ & $28(35,9 \%)$ \\
$5-10 \%$ & $12(15,4 \%)$ \\
$>10 \%$ & $11(14,1 \%)$ \\
\hline Performance status WHO & $45(57,7 \%)$ \\
0 & $22(28,2 \%)$ \\
1 & $41(52,6 \%)$ \\
2 & $37(47,4 \%)$ \\
\hline Stage & $61(78,2 \%)$ \\
III & $11(14,1 \%)$ \\
IV & $6(7,7 \%)$ \\
\hline Histology & $51(65,4 \%)$ \\
Squamous & $27(34,6 \%)$ \\
Adenocarcinoma & \\
Large- cell & \\
\hline HB level & \\
Normal & \\
Anemia & \\
\hline & \\
\hline
\end{tabular}

Table 2. Objective responses

\begin{tabular}{|l|c|c|c|c|c|}
\hline $\begin{array}{l}\text { Patients/ } \\
\text { Response }\end{array}$ & CR & PR & NC & PD & ORR\% \\
\hline 78 & 4 & 21 & 34 & 16 & $32,1 \%$ \\
\hline
\end{tabular}

$\mathrm{ORR}=\mathrm{CR}+\mathrm{PR}$

CR, Complete response; PR, Partial response; NC, No change; PD, Progressive disease; ORR, Overall response rates;

Table 3. Relation between survival and anemia level

\begin{tabular}{|l|c|c|c|}
\hline Anemia & N & OSS & $p$ \\
\hline Mild & 11 & 7,7 & $<0,05$ \\
\hline Moderate & 12 & 6,3 & $<0,05$ \\
\hline Severe & 4 & 4,4 & $<0,05$ \\
\hline Normal & 51 & 11,3 & $<0,05$ \\
\hline
\end{tabular}

$\mathrm{N}$ : number of patients, MSS: overall survival time, months,

Severe: $<11 \mathrm{~g} / \mathrm{L}$ in men and $<10 \mathrm{~g} / \mathrm{L}$ in women, Moderate: $<11$ $12 \mathrm{~g} / \mathrm{L}$ in men and $<10-11 \mathrm{~g} / \mathrm{L}$ in women, Mild: $<12-13 \mathrm{~g} / \mathrm{L}$ in men and $<10 \mathrm{~g} / \mathrm{L}$ in women, Normal $>13 \mathrm{~g} / \mathrm{L}$ in men and $<11 \mathrm{~g} /$ $\mathrm{L}$ in women

Table 4. Multivariate analysis and prognostic factors by Cox proportional hazard ratio

\begin{tabular}{|l|c|c|c|}
\hline Variables & HR & $95 \%$ CI & P-value \\
\hline Anemia & 1 & & \\
Normal & 1,42 & $1,18-1,67$ & $<0,001$ \\
\hline $\begin{array}{l}\text { Stage by TNM } \\
\text { classification }\end{array}$ & & & \\
IV & 1 & & \\
III & 0,68 & $0,49-0,96$ & $<0,001$ \\
\hline WHO PS & 1 & & \\
2 & 0,55 & $0,39-0,86$ & $<0,001$ \\
1 & 0,41 & $0,28-0,69$ & $<0,001$ \\
0 & 1 & & \\
Sex & 0,68 & $0,44-1,02$ & NS \\
Male & 1 & & \\
Female & 0,69 & $0,44-0,92$ & NS \\
\hline Histology & $0,36-1,08$ & NS \\
$\begin{array}{l}\text { Squamous } \\
\text { Adenocarcinoma }\end{array}$ & & \\
Large- cell & 0,55 & $0,59-1,12$ & NS \\
\hline $\begin{array}{l}\text { Age years } \\
<60\end{array}$ & 1 & & \\
$>60$ & 0,84 & 0 & \\
\hline
\end{tabular}

HR- Hazard ratio, Ps- performance status, TNM- tumornodes- metastases 
Table 5. Relation between anemia and other clinicpathologic factors

\begin{tabular}{|l|c|c|c|}
\hline Variables & Normal & Anemia & P value \\
\hline Age, years & 78 & 27 & \\
$<60$ & 34 & 8 & \\
$>60$ & 44 & 19 & NS \\
\hline Sex & 66 & 24 & \\
Men & 12 & 4 & NS \\
Women & 56 & 17 & \\
\hline WHO PS & 22 & 11 & $<0,001$ \\
$0-1$ & & & \\
2 & 41 & 13 & $<0,001$ \\
\hline Clinical stage & 37 & 15 & \\
III & & & \\
IV & 61 & 22 & \\
\hline Histology & 11 & 4 & NS \\
Squamous & 6 & 1 & \\
Adenocarcinoma & & & \\
Large-cell & & &
\end{tabular}

\section{REFERENCES:}

1. Jemal A., R. Siegel, E. Ward, Hao Y, $\mathrm{Xu}$ J, Thun MJ. Cancer statistics, 2009, CA: Cancer $J$ Clinicians, 2009 JulAug;59(4):225-49. Epub 2009 May 27. [CrossRef] [PubMed]

2. Rapp E., J. L. Pater, A. Willan, Cormier Y, Murray N, Evans WK, et al, Chemotherapy can prolong survival in patients with advanced non-small-cell lung cancer- report of a Canadian multicenter randomized trial. J Clin Oncol. 1988 Apr;6(4):633- 641,. [PubMed]

3. Bunn PA Jr, Kelly K. New chemotherapeutic agents prolong survival and improve quality of life in non small cell lung cancer: a review of the literature and future directions, Clin Cancer Res, 1998 May; 4(5):1087- 1100. [PubMed]

4. Schiller JH, Harrington D, Belani CP, Langer C, Sandler A, Krook J, et al, Comparison of four chemotherapy regimens for advanced non-small-cell lung cancer, $N$ Eng J Med. 2002 Jan;346(2):92-98, [CrossRef][PubMed]

5. O’Connell J., Kris M., Gralla R., Groshen S, Trust A, Fiore JJ, et al, Frequency and prognostic importance of pretreatment clinical characteristics in patients with advanced non-small- cell lung cancer treated with combination chemotherapy, J Clin Oncol, 1986 Nov;4(11):1604- 17. [PubMed]

6. Tesarova P, Kvasnicka J., [Treatment of anemia in patients with tumors]. Cas Leuk Ces 1995 Oct 18;134(20):647- 50. [Article in Czech] [PubMed]

7. De Rienzo DP, Saleem A. Anaemia of chronic disease: a review of pathogenesis. Texas Med 1990 Oct;86(10):80- 3. [PubMed]

8. Ludwig H, Fritz E. Anemia in cancer patients. Semin Oncol 1998 Jun;25(3 Suppl 7):2- 6. [PubMed]

9. Glaspy J, Bukowski R, Steinberg D, Taylor C, Tchekmedyian S, Vadhan-Raj S. Impact of therapy with epoetin alpha on clinical outcomes in patients with nonmyeloid malignancies during cancer chemotherapy in community oncology practice. J Clin Oncol. 1997 Mar;15(3):1218 -34. [PubMed]

10. Miller AB, Hoogstraten B, Staquet M, Winkler A.. Reporting results of cancer treatment. Cancer. 1981 Jan 1;47(1):207214. [PubMed]

11. Brimdage MD, Pater JL, Zee B. Assessing the reliability of two toxicity scales: Implications for interpreting toxicity data. J Natl Cancer Inst. 1993 Jul
21;85(14)1138-48. [CrossRef] [PubMed]

12. Kaplan EL, Meier P, Nonparametric estimation from incomplete observations. J Am Stat Assoc 1959; 53; 457- 481

13. Crino L, Tonato M, Darwis $\mathrm{S}$, Meacci ML, Corgna E, Di Costanzo F, et al., A randomized trial of 3 cisplatin containing regimens in NSCLC. A study of the Umbrian Lung Cancer Group, Cancer Chemother Pharmacol. 1990 26(1):52-56. [PubMed]

14. Weick J, Crowley J, Natale RB, Hom BL, Rivkin S, Coltman CA Jr, et al. A randomized trial of five cisplatin- containing treatments in patients with metastatic nonsmall- cell lung cancer: A Southwest Oncology group study. J Clin Oncol. 1991 Jul; 9(7):1157- 1162. [PubMed]

15. Knight K, Wade S, Balducci L. Prevalence and outcomes of anemia in cancer: a systemic review of the literature, Am J Med. 2004 Apr 5;116 Suppl 7A 11S16S. [CrossRef] [PubMed]

16. Caro J., Salas M., Ward A. Goss G. Anemia as independent prognostic factor for survival in patients with cancer. A systemic, quantitative review, Cancer. 2001 Jun 15;91(12):2214- 2221. [PubMed]

\section{Address for correspondence:}

Dr. Deyan Nikolov Davidov, Department of Chemotherapy, Oncological Center, Medical University; 1 “St. Kliment Ohridsky" Str., 5000 Pleven, Bulgaria; Phone: +359/64/886 138, Fax: +359/64/831634; E-mail: dean_davidov@abv.bg 